\title{
Digenetic Trematodes: an existence as parasites. Brief general overview
}

\author{
Marco Crotti
}

Faculty of Zoology, University of Derby, Derby - East Midlands, U. K.

Key words: Digenea, Economic impacts, Life-cycles, Trematodes

\section{I trematodi digenei: un'esistenza come parassiti. Breve rassegna con panoramica generale}

\section{SUMMARY}

Digenea is a wide and diverse group of trematodes, whose members are able to parasitize all classes of vertebrates, and several groups of invertebrates. While the usual life-cycle involves three hosts, a great number of species has evolved to increase or to reduce the number of hosts during development, in order to be more successful in their ecological niche. Differently from other trematodes, digenetic flukes can infect humans, and this process can cause severe diseases like schistosomiasis, which infects around 200 million people worldwide. Finally, digenetic trematodes are not only a threat to humans' health, but also to the economy, causing millions of dollars losses in activities such as aquaculture and animal husbandry.

\section{INTRODUCTION}

Digenetic trematodes, commonly known as flukes, are the most diverse group of platyhelminths (6). Their number is estimated to be around 18000 species (30), and all are obligate parasites of vertebrates (12). The great peculiarity of this taxon that separates it from other trematode groups is the complex life cycle. First of all, all digenetic trematodes, during their development, have at least one parasitic stage in a mollusc and a parasitic stage in a vertebrate (44). Usually the basic life-cycle pattern of a digenetic fluke involves three hosts (5). According to Cheng (6) a generalised life cycle is as follows: in the final host, a vertebrate, the parasite reaches sexual maturity and releases eggs, which are expelled through faeces; each egg develops into a miracidium larva, the first free-living stage of the development, which infects the first intermediate host, a mollusc (usually a snail); in the snail the miracidium metamorphoses into a sac-like sporocyst, which undergoes asexual reproduction to produce the next stage in the life-cycle, a redia; the redia then produce the second free-living stage, the cercaria; the cercaria leaves the snail and actively search, thanks to chemical and physical signals (19), the second intermediate host (usually an arthropod, sometimes a vertebrate); in the second host the cercaria develops into metacercaria, a miniature of the adult form; the secondary host is then eaten by another animal, the final or definitive host; inside the final host the metacercaria reaches sexual maturity and the cycle starts again. Another feature of digenetic trematodes is their ability to infect domestic animals and humans, thus representing a serious threat to health and the economy, especially in developing countries (22).

In humans digenetic flukes can cause serious diseases, such as fascioliasis (41), once restricted but now expanded to all continents (15), and schistosomiasis (34), considered the most serious parasitic disease after malaria, and responsible for the infection of more than 200 million people worldwide (34). This essay looks at some aspects of digenetic trematodes diversity, such as the variation in the life-cycle, at the variety of trematodes that infect humans, and finally at the economic impact of digenetic flukes (14).

\section{DIVERSITY OF LIFE-CYCLES}

The majority of digenetic trematodes infect three hosts during their life-cycle. However, some species require a further additional host to be able to reach sexual maturity; these species have a four-host life cycle. Some members of the Halipegus genus have been observed to infect four hosts during their development. Zelmer, et al (45) have described the complex development of Halipegus occidualis. This species is a parasite of green frogs, and it is found in North America.

The eggs are expelled by frogs and are ingested by snails. Once the cercaria leaves the mollusc, it penetrates the secondary intermediate host, a crustacean (ostracods). The crustaceans are a food source for dragonfly larvae, the third intermediate

\section{Corresponding author: Marco Crotti}

62, Manchester Street, DE223GA Derby - East Midlands, U. K.

Tel. 00447403523 I 35

E-mail:marioche@hotmail.it 
host. However, Zelmer, et al (45) found out that the insect larva is not a physiological requirement for the further development of the trematode, but instead is an ecological necessity in order for the trematode to reach the definitive host (green frogs do not feed on ostracods, but do feed on dragonfly larvae). Halipegus eccentricus has been observed to use four hosts during its life-cycle as well (4). Differently from its relative $H$. occidualis, $H$. eccentricus, instead of relying on dragonfly larvae to bridge the trophic gap, infects damselfly larvae. A four-host life cycle is also found in the trematode Lecithocladium excisum, a common parasite of Scomber spp. (24). The miracidium infects an opistobranch snail as primary host.

The cercaria is then ingested by small crustaceans, the copepods. The copepods are then eaten by other zooplanktonic organisms, such as ctenophores or juveniles polychaetes, which are then ingested by the fish.

Other species instead have evolved a much simpler life-cycle. In some case it has been observed a two-host or even a single host lifecycle pattern (10). It is not known the exact reason behind this shortening, but a reduced number of hosts has its benefits (33): for example, if one of the hosts is temporarily rare due to other ecological reasons, skipping one parasitic stage allows for the completion of the development; moreover, a reduced number of hosts results in a reduced risk during the host switching phase. According to Poulin and Cribb (33) there are five main ways trematodes can achieve simpler lifecycles.

The first way is known as progenetic development, where the metacercaria, once is encysted inside the second intermediate host, develops precociously into an adult, reaching sexual maturity and releasing eggs. Examples of this development are some species in the genus Alloglossidium, in which all trematodes produce eggs in their second and final hosts (which can be crustaceans or leeches) (38).

A second type of truncation consists of using the first intermediate host, the mollusc, as a second intermediate host. Cercariae do not leave the mollusc; instead they develop into metacercariae inside the first host and wait to be ingested by the final host. Members of the Lissorchiidae family, such as Asymphylodora tincae, have been observed to follow this life-cycle pattern (28).

Another way to achieve an abbreviation in the life-cycle is to use the second intermediate host as a definitive host as well. Similarly to progenetic development, this process eliminates the third host stage. For example, cercariae of Haplometra cylindracea penetrate the oral cavity of frogs where they encyst as metacercariae in the buccal mucosa; after few days the cysts containing the metacercariae burst and the trematodes migrate to the frogs' lungs, where they reach adult stage (17). In the fourth type of truncation, adult worms develop inside rediae or sporocysts within the mollusc and release eggs, which then develop into miracidia. The miracidium will then infect another mollusc. This is a single-host life-cycle.

Barger and Esch (1) report the ability of Plagioporus sinitsini to switch from a normal three-host life cycle to a single-host one if the fish it infects is absent from the environment.

Finally, the fifth way, a single-host development, occurs only in some members of the Cyathocotylidae family, such as Mesostephanus haliasturis (2). In this process, the sporocyst inside the mollusc can directly produce miracidia, which are thought to infect another snail, thus continuing the life-cycle.

\section{DIVERSITY OF TREMATODES IN \\ HUMANS}

A great variety of digenetic trematodes is capable of infecting humans. In some cases humans are the final target of the trematode (e.g. 18), in others infection occurs accidentally (e.g. 9).

The consequences of a fluke infection in humans are different, and depend on the trematode species involved and the habitat they live in inside the host. Parija (31) classified trematodes according to their habitat inside the infected organism, and came up with four different groups: blood flukes, living inside the blood vessels, liver flukes, lung flukes, and intestinal flukes.

Schistosoma is a genus of blood trematodes which cause the tropical disease schistosomiasis or bilharzia (31). The main species that infect humans are S. haematobium, found in Africa and Arabia peninsula, S. mansoni, found in Africa, Arabia peninsula and South America, and $S$. japonicum, found in South-East Asia (31). Infection occurs when working or bathing in water where the snail host is present (18). The cercariae actively search humans and penetrate the host through the skin (18). S. haematobium causes inflammation and obstruction of the urinary system, while the other two species are responsible for intestinal and hepatosplenic inflammations (18).

Schistosomiasis is endemic in 74 countries, the majority of which are classified as developing, and increase in population plus poor medical conditions might result in a further spread of the disease (7).

Liver flukes are food-borne diseases that result from ingestion of infected food. Among the most 
common we find Fasciola hepatica, Clonorchis sinensis and Opistorchis viverrini (16).

$F$. hepatica is responsible for fascioliasis, a disease once thought to be prevalently of veterinary importance, but now recognised as an important human infection, with the highest rate of cases in developing countries $(8,9)$. There are two recognised pathological stages: an acute stage coinciding with metacercaria migration and maturation in the hepatic tissue, which causes disruption and inflammation of those tissues, and a chronic stage corresponding to the persistence of the trematode in the bile ducts, which causes several symptoms such as fever, abdominal pain, anaemia and intestinal disturbance (20).

$C$. sinensis and $O$. viverrini are both members of the Opisthorchiidae family, and are widespread in south-east Asia. Eating raw freshwater fish harbouring metacercariae is the cause of infection for these two parasites $(21,39)$ and the main symptoms of the disease are epigastric pain, loose stool, fever, loss of appetite, general malaise, and increase the risk of cholangiocarcinoma, a fatal bile duct cancer $(21,39)$.

Opistorchis felineus is a close relative of $O$. viverrini, and it is commonly found in east Europe, where it is responsible for the majority of helminthiases of the liver (27). However, this species has been recently recorded in southern Europe, such as Spain (37) and Italy (11).

Paragonimus spp. are some of the most common species of lung flukes. More than 30 species have been described in this genus, but only seven can infect humans (13). P. westermani is the most important and widespread species of the genus, found in Africa, Asia and South America (31). Human infection occurs by ingestion of infected crustaceans or raw meat from paratenic mammals host (3).

In most species the trematode develops in the lungs, causing inflammation of the respiratory system (3). In more rare cases, Paragonimus spp can cause cerebral paragonimiasis, whose symptoms are headache, visual disturbance, seizures, motor and sensory disturbance, mental deterioration, and it is more dangerous than normal paragonimiasis (29).

Gastodiscoides hominis and Echinostoma spp are two examples of intestinal flukes. G. hominis causes gastrodiscoidiasis, an intestinal infection which is rarely fatal, but can cause abdominal pain and intestinal discomfort due to the mechanical and toxic effect of the parasite (14, 23). Echinostomiasis instead is a serious intestinal infection, which manifests as damage to the intestinal mucosa, thus resulting in extensive duodenal erosion and catarrhal inflammation (36).
Main symptoms of the disease are anaemia, headache, stomach-ache, loss of weight, urinary incontinence, gastric pain (36).

\section{ECONOMIC IMPACT OF TREMATODES}

Since digenetic trematodes are able to infect all vertebrate groups, they pose a serious threat to those economical activities involving vertebrate taxa, such as fishing, aquaculture and animal husbandry.

Voutilainen et al (43) state that parasitic infections are responsible for great economic losses in aquaculture, in terms of reduced fish growth and increase in mortality rate, and in terms of investments for adequate farming techniques and necessary chemicals used to prevent and fight off infections.

Some Authors, in a study looking at the parasite fauna of eight economical important flatfishes in Northern Spain, found 13 digenetic trematode species infecting the fish; this discovery should push for better aquaculture management, since northern Spain is one of the main exporters of flatfishes in Europe. Northern Bluefin Tuna, the most valuable species in aquaculture, has been reported as well to host a wide range of trematode parasites, which affect the growth and survival of individuals (26). Furthermore, Menzies et al (25) report that economic losses due to cataracts in farmed Atlantic Salmon Salmo salar, caused by trematodes of the genus Diplostomum, are estimated to be around 27 million Euros just in Europe.

Parasitic infections are also a cause of disease and loss in productivity in animal husbandry activities worldwide (42). It is well established that helminthiases can cause retarded growth and increase mortality rate (23), and fascioliasis due to Fasciola gigantica has been observed to be a source of these symptoms in ruminants (32). Furthermore, Ross (35) reported that fascioliasis infections in cattle are able to reduce milk production of $14 \%$. Fascioliasis can also result in economic losses in terms of condemned meat.

A study by Swai and Ulicky (40) in abattoirs in Tanzania showed that profits losses due to condemnation of meat as a result of fascioliasis can amount to thousands of dollars even in a single slaughterhouse.

\section{REFERENCES}

1. Barger MA, Esch GW. Plagioporus sinitsini (Digenea: Opecoelidae): a one-host life cycle. Journal of Parasitology. 2000; 86: 150-3.

2. Barker SC, Cribb TH. Sporocysts of Mesostephanus haliasturis (Digenea) produce miracidia. International Journal for Parasitology. 1993; 23: 137-9. 
3. Blair D. Genomes of Paragonimus westermani and related species: current state of knowledge. International Journal for Parasitology. 2000; 30: 421-6.

4. Bolek MG, Tracy HR, Janovy JJ. The role of Damselflies (Odonata: Zygoptera) as paratenic hosts in the transmission of Halipegus eccentricus (Digenea: Hemiuridae) to Anurans. Journal of Parasitology. 2010; 96: 724-35.

5. Bush AO, Fernandez JW, Esch GW, Seed JR. Perspective in parasitology: The ecology and diversity of parasites. Cambridge: Cambridge University Press, 2001.

6. Cheng TC. General Parasitoly (2edn), 1986. Florida: Academic Press.

7. Chitsulo L, Engels D, Montresor A, Savioli L. The global status of schistosomiasis and its control. Acta Tropica. 2000; 77: 41-51.

8. Coma SM, Bargues MD, Valero MA. Fascioliasis and other plant-borne trematode zoonoses. International Journal for Parasitology. 2005; 35: 1255-78.

9. Coma SM, Esteban JG, Bargues MD. Epidemiology of human fascioliasis: a review and proposed new classification. Bulletin of the World Health Organization. 1999; 77: 340-6.

10. Combes C. Parasitism: Ecology and Evolution of Intimate Interaction. Chicago: University of Chicago Press; 2001.

11. Crotti D, D'Annibale ML, Crotti S. Opistorchiasi autoctona del Lago Trasimeno (Perugia): descrizione di due episodi epidemici da Opistorchis felineus e problematiche diagnostiche differenziali. Microbiologia Medica. 2007; 42: 36-41.

12. Dawes B. The trematoda (edn), 1946; United Kingdom: Cambridge University Press.

13. Doanh PN, Dung DT, Thach DTC, Horii Y, Shinohara A, Nawa Y. Human paragonimiasis in Vietnam: Epidemiological survey and identification of the responsible species by DNA sequencing of eggs in patients sputum. Parasitology International. 2011; 60: 534-7.

14. Esch GW, Barger MA, Fellis KJ. The transmission of digenetic trematodes: style, elegance, complexity. Integrative and Comparative Biology. 2002; 42: 30412.

15. Esteban JG, Flores A, Aguirre C, Strauss W, Angles R, Coma SM. Presence of very high prevalence and intensity of infection with Fasciola hepatica among Aymara children from the Northern Bolivia Altiplano. Acta Tropica. 1997; 66: 1-14.

16. Fried B, Graczyk TK, Tamang L. Food-borne intestinal trematodiases in humans. Parasitological Resources. 2004; 93: 159-70.

17. Grabda-Kazubska B. Abbreviation of the life cycles in plagiorchid trematodes: general remarks. Acta Parasitologica Polonica. 1976; 24: 125-41.

18. Gryseels B, Polman K, Clerinx J, Kestens L. Human schistosomiasis. Lancet. 2006; 368: 1106-18.

19. Haas W. Physiological analyses of host-finding behaviour in trematode cercariae: adoptions for transmission success. Parasitology. 1994; 109: 15-29.

20. Haseeb AN, el-Shazy AM, Arafa MA, Morsy AT. A review of fascioliasis in Egypt. Journal of the Egyptian Society of Parasitology. 2002; 32: 317-54.

21. Hong ST, Fang Y. Clonorchis sinensis and clonorchiasis, an update. Parasitology International. 2012; 61: 17-24.

22. Keiser J, Utzinger J. Chemotherapy for major foodborne trematodes: a review, Expert Opinion on Pharmacotherapy. 2004; 5: 1711-26.

23. Khan MN, Sajid MS, Khan MK, Iqbal Z, Hussain A.
Gastrointestinal helminthiasis: prevalence and associated determinants in domestic ruminants of district Toba Tek Singh, Punjab, Pakistan. Parasitological Resources. 2010; 107: 787-94.

24. Koie M. Aspects of the morphology and life cycle of Lecithocladium excisum (Digenea, Hemiuridae), a parasite of Scomber spp. International Journal for Parasitology. 1991; 21: 597-602.

25. Menzies FD, Crockford T, Breck O, Midtlyng PJ. Estimation of direct costs associated with cataracts in farmed Atlantic Salmon (Salmo salar). Bulletin of European Association of Fish Pathologists. 2002; 22: 27-32.

26. Mladineo I, Segvic T, Petric M. Do captive conditions favour shedding of parasites in the reared Atlantic Bluefin tuna (Thunnus thynnus)? Parasitology International. 2011; 60: 25-33.

27. Mordvinov VA, Yurlova NI, Ogovodova LM, Katokhin AV. Opistorchis Felineus and Metorchis, bilis are the main agents of liver fluke infection of humans in Russia. Parasitology International. 2012; 61: 25-31.

28. Nasincova V, Scholz T. The life cycle of Asymphylodora tincae (Modeer 1790) (Trematoda: Monorchiidae): a unique development in monorchiid trematodes. Parasitology Research. 1994; 80: 192-7.

29. Oh SJ. Cerebral paragonimiasis. Journal of the Neurological Sciences. 1969; 8: 27-48.

30. Olson PD, Cribb TH, Tkach VV, Bray RA, Littlewood DTJ. Phylogeny and classification of the Digenea (Platyhelminthes: Trematoda). International Journal for Parasitology. 2003; 33: 733-55.

31. Parija SC. Trematode Infection, Medscape [online], 2011; Available at http://emedicine.medscape.com. (Accessed: 05 March 2013).

32. Phiri AM, Phiri IK, Sikasunge CS, Mourad J. Prevalence of fasciolosis in Zambian cattle observed at selected abattoirs with emphasis on age, sex and origin. Journal of Veterinary Medicine Series B. 2005; 52: 414-6.

33. Poulin R, Cribb TH. Trematode life cycles: short is sweet? Trends in Parasitology. 2002; 18: 176-83.

34. Rollinson D, Knopp S, Levitz S, et al. Time to set the agenda for schistosomiasis elimination. Acta Tropica, 2012; doi.10.1016/j.actatropica.2012.04.013.

35. Ross JG. The economics of Fasciola hepatica infections in cattle. British Veterinary Journal, 1970; 126: $13-5$.

36. Sajuntha W, Sithithaworn P, Duenngai K, Kiatsopit N, Andrews RH, Petney TN. Genetic variation and relationshisps of four species of medically important echinostomes (Trematoda: Echinostomatidae) in South-East Asia. Infection, Genetics and Evolution, 2011; 11: 375-81.

37. Segovia JM, Torres J, Miquel J. The red fox, Vulpes vulpes L., as a potential reservoir of zoonotic flukes in the Iberian Peninsula. Acta Parasitologica, 2002; 42: 36-41.

38. Smythe AB, Font WF. Phylogenetic analysis of Alloglossidium (Digenea: Macroderoididae) and related genera: life-cycle, evolution and taxonomic revision. Journal of Parasitology. 2001; 87: 386-91.

39. SripaB, Nawa Y, Sithithaworn P, Andrews R, Brindley PJ. Discovery of human opistorchiasis: A mysterious history. Parasitology International, 2012; 61: 3-4.

40. Swai ES, Ulicky E. An evaluation of the economic losses resulting from condemnation of cattle livers and loss of carcass weight due to fasciolosis: a case study from Hai town abattoir, Kilimanjaro, Tanzania. Livestock Research for Rural Development. 2009; 21: 
Article 186.

41. Valero MA, Crespo IP, Khoubbane M, et al. Fasciola hepatica phenotypic characterization in Andean Human endemic areas: Valley versus altiplanic patterns analysed in liver flukes from sheep from Cajamarca and Mantaro, Peru. Infections, Genetics and Evolution. 2012; 12: 403-10.

42. Vercruysse J, Claerebout E. Treatment vs nontreatment of helminth infections in cattle: defining threshold. Veterinary Parasitology. 2001; 98: 195-214.
43. Voutilainen A, Valdez H, Karvonen A, et al. Infectivity of trematode eye flukes in farmed salmonid fish Effects of parasite and host horigins, Aquaculture, 2009; 293: 108-12.

44. Wright CA. Flukes and Snails, (1971) London: George Allen and Unwin LTD.

45. Zelmer DA, Wetzel EJ, Esch GW. The role of habitat in structuring Halipegus occidualis metapopulations in the green frog. Journal of Parasitology. 1999; 85: 19-24. 